\title{
A representação cultural de um "parto natural": o ordenamento do corpo grávido em meados do século XX
}

\author{
The cultural representation of "natural childbirth": \\ the outlook on the pregnant body in the mid-twentieth century
}

Lilian Fernandes Arial Ayres ${ }^{1}$

Bruno David Henriques ${ }^{1}$

Wellington Mendonça de Amorim ${ }^{2}$

${ }^{1}$ Departamento de Medicina e Enfermagem, Universidade Federal de Viçosa. Av. Peter Henry Rolfs s/n, Campus Universitário. 36570900 Viçosa MG Brasil. liliayresenf@yahoo.com.br ${ }^{2}$ Diretoria de PósGraduação, Universidade Federal do Estado do Rio de Janeiro. Rio de Janeiro RJ Brasil.

\begin{abstract}
The scope of this study is to discuss teaching strategies directed towards women to institutionalize the representation of normal birth based on the work "Natural Childbirth: A Guide for Future Parents", published in 1955. The research begins with a historical and cultural anal$y$ sis of the 1955, 1957, 1960 and 1964 editions of this book. It is aided by materials published, in the same period, which share the same meanings and representations concerning issues surrounding childbirth in the Brazilian context. It is a period marked by retrospectives and the emergence of methods for preparing women for the childbirth process. The results of our analysis, in the light of Roger Chartier's theoretical framework, especially applying the notion of representation of Michel Foucault, indicate that the apparatuses used in the work's registers sought to propose a disciplinary model for childbirth: institutionalization, medical insertion and industrialization of normal childbirth in the Brazilian context of the mid-twentieth century.
\end{abstract}

Key words Natural childbirth, History, Obstetrics, Human body, Institutionalization
Resumo O objetivo deste estudo foi discutir as estratégias pedagógicas destinadas às mulheres para institucionalização da representação do parto normal a partir da obra Parto Natural: Guia para os futuros pais, publicada em 1955. Partiu-se de uma análise histórica e cultural desse livro em suas edições publicadas nos anos de 1955, 1957, 1960 e 1964, auxiliada por materiais publicados à época que compartilhavam das mesmas significações e representações referentes às questões do parto no contexto brasileiro. Esse período foi marcado pelo resgate e surgimento de métodos de preparação da mulher para o processo de parir. A análise, à luz do referencial teórico de Roger Chartier, principalmente com a noção de representação, $e$ de Michel Foucault, indica que os dispositivos utilizados na tessitura da obra visaram propor um modelo de parto disciplinar, a institucionalização, medicalização e industrialização do parto normal no contexto brasileiro em meados do século XX. Palavras-chave Parto normal, História, Obstetrícia, Corpo humano, Institucionalização 


\section{Introdução}

Evidências científicas comprovam que boas práticas durante o parto favorecem resultados efetivos para redução da morbimortalidade materna, fetal e neonatal. Em contrapartida, intervenções como a posição supina, o uso de ocitocina/cateter intravenoso, a episiotomia, a pressão no fundo do útero, a ruptura das membranas ovulares, entre outras, podem trazer danos à saúde quando utilizadas sem necessidade. Sabe-se que o corpo da mulher está apto para dar à luz, e na maior parte das vezes não requer o uso desses procedimentos ${ }^{1}$.

A pesquisa Nascer no Brasil, com 23.894 mulheres, ratifica a necessidade de mudar o atual modelo obstétrico brasileiro ${ }^{2}$. Ela demonstra a supremacia do uso das tecnologias e intervenções obstétricas que prejudicam o binômio mãe-bebê e o aumento das taxas elevadas de cesariana entre as mulheres brasileiras de baixo risco ${ }^{2,3}$. Esse modelo obstétrico é considerado um problema de saúde pública, heterogêneo e multifatorial. Entre as causas, citam-se: o protagonismo dos profissionais de saúde no cenário do parto, as armadilhas do sistema de saúde que tornam a cesariana mais conveniente para os profissionais de saúde, a percepção de uma parte da população sobre a superioridade dessa via de parto $^{3} \mathrm{e}$ a falsa necessidade do uso rotineiro de procedimentos obstétricos.

O processo histórico em que se deu a formação desse modelo no Brasil começou principalmente a partir do século XX. Segundo a Organização Mundial de Saúde, a legitimação do médico como ator predominante na assistência ao parto veio acompanhada de uma prática que tem o propósito de interferir, acelerar, regular ou monitorar o processo fisiológico do parto ${ }^{4}$. A hospitalização da parturiente foi essencial para a apropriação e o desenvolvimento do saber médico, o que gerou a medicalização do seu corpo ${ }^{5}$. $\mathrm{Na}$ contramão de um parto hipermedicalizado, emergem diversos movimentos em defesa de um parto natural. Essa temática vem angariando espaço, e percebe-se o aumento da demanda por partos domiciliares como alternativa de parto e nascimento de modo natural.

Esse contexto chamou atenção, ao entrar em contato com a tessitura do livro Parto Natural: Guia para os futuros pais ${ }^{6}$. O livro, escrito pelo obstetra americano Frederick Goodrich, foi publicado pela primeira vez no Brasil em 1955. Foi como em um romance: aos poucos percebeu-se o aparecimento das normas mais elementares de um comportamento ordenado para gestar, parir e maternar em meados do século XX, que se mantém até hoje.

O universo cultural de representações de cuidados prescritos à mulher durante o processo delimitado pela obra Parto Natural, inclusive na prática dos serviços de saúde no Brasil, é tecido por inúmeras palavras que representam, na maioria das vezes, uma ordem, uma norma, uma prescrição, um controle: cuidado, pré-natal, saúde, alimentação, relaxamento, exercício, corpo, parto, amamentação, preparo e orientação. A obra é marcada por duas situações antagônicas: heteronomia e autonomia; dito de outra maneira, ativo e passivo.

Acredita-se que o livro Parto Natural é constituído por um conjunto de condutas que determinam que as mulheres devem vigiar seus corpos a cada fase do ciclo gravídico puerperal. Esse autocontrole visa promover e garantir a saúde perfeita do recém-nascido, a felicidade da família e a melhoria da nação. Sabe-se que os médicos, durante o século XX, estavam preocupados em produzir manuais educativos dirigidos para as famílias. Nesse período, os investimentos na saúde e na educação eram percebidos como estratégicos para obter uma população potente e apta para trabalhar ${ }^{7}$, e eliminar os problemas de conduta desde a concepção, o nascimento até a infância era uma preocupação das famílias, das escolas e do governo ${ }^{7-10}$.

Essa ideia de promoção de uma nação sadia e feliz pode ser certificada na obra Parto Natural, como demonstra o fragmento: "O objetivo da arte e ciência obstétricas pode ser resumido no duplo objetivo: mães e crianças sadias, e mães e crianças felizes"'. Acrescenta-se que naquela época os médicos percebiam suas ações como capazes de formar uma pátria composta por indivíduos saudáveis ${ }^{11}$. A medicina é uma "instituição regulamentada como conjunto de indivíduos que constituem o corpo médico, como saber e prática, como competência reconhecida pela opinião pública, a justiça e a administração"12. Portanto, esses profissionais são investidos de autoridade, reconhecimento, visibilidade e saber, perante a sociedade, e anunciam estratégias pedagógicas por intermédio dos materiais impressos.

Compreende-se que os intelectuais, por meio dos livros, podem modificar a visão do mundo social e também transformar o próprio mundo social; podem agir a distância, ao mudar as visões de mundo, as práticas cotidianas e o modo de amamentar, de pensar e de falar ${ }^{13}$. Durante o século XX, muitos livros com prescrições de cui- 
dados enunciados por médicos foram produzidos no Brasil e entende-se como cuidado a prática cultural que visa reconhecer uma identidade social, exibir uma maneira de estar no mundo e significar simbolicamente um estatuto, uma ordem, um poder e uma posição $0^{14,15}$.

Acompanhando esse pensamento e acreditando que "a família inculca modos de pensar e de atuar que se transforma em hábitos"16, ela pode ser reconhecida como uma instituição social. A família possui um papel fundamental na transmissão de preceitos sociais e na imposição do padrão ideal de comportamentos e hábitos ${ }^{17}$. Este estudo apresenta a obra o Parto Natural, que tinha como alvo a mulher inserida na família. Ao folheá-la, nota-se a instituição de um conjunto de normas a serem lidas, manejadas, apreendidas e praticadas.

Além disso, depreende-se que esse livro fomenta um movimento em favor da melhoria da assistência obstétrica, do parto normal e do incentivo da autonomia da mulher nos anos de 1950 e 1960. No entanto, é interpelado pelo fortalecimento de um modelo tecnocrático, marcado pelo aumento da cesariana e pela institucionalização do parto e centrado na figura médica em meados do século $X^{1,10,18-20}$. É intrigante tentar compreender a intencionalidade de produzir um livro que estimulasse a preparação da mulher para o parto normal. Enfim, será que ele realmente enunciava um parto natural?

Torna-se imprescindível estabelecer uma relação próxima com a obra, tomada pela ousadia de apreender os dispositivos que evidenciam as visões de mundo sobre o parto. De certo, as representações contidas nesse livro estavam diretamente conectadas aos interesses de um grupo que buscava o ordenamento do campo obstétrico, a institucionalização de uma identidade, o parto e o controle do corpo e da mente da mulher.

Acredita-se que revisitar a obra é demonstrar como o uso abusivo das intervenções obstétricas, de um parto industrializado, está arraigado nas normas culturais e se sustenta na atualidade. Um modelo de parto rico em mitos que são justificados pelo bem-estar das mulheres e dos seus futuros filhos. Diante do exposto, objetivou-se discutir as estratégias pedagógicas destinadas às mulheres para institucionalização da representação do parto normal a partir da obra Parto Natural: Guia para os futuros pais, publicada em 1955.

\section{Metodologia}

Trata-se de um estudo com base na abordagem da História Cultural, em que foram utilizados textos de Roger Chartier e Michel Foucault. Foi feita uma análise histórica da parturição, em meados do século XX, a partir da obra Parto Natural. Depreende-se que em distintos lugares e momentos uma realidade social é construída, pensada e dada a ler ${ }^{14}$. A história cultural converge-se para uma nova maneira de questionar a realidade, trazendo como referencial os problemas de pesquisas relacionados com a cultura e destacando a função das representações. É um domínio que objetiva compreender como as relações de desigualdade e de dominação se exprimem e são alimentadas por sistemas de representações que podem comandar pela reprodução do sistema e, mais raramente, pela ruptura ${ }^{14}$.

Apontam-se alguns caminhos para o entendimento das representações, que nem sempre estão visíveis e claras. Para isso, preconizam-se as classificações, divisões e delimitações que organizam a apreensão do mundo social como categorias fundamentais de percepção e de apreciação do real. São os esquemas intelectuais (instituições sociais), geradores desses sistemas de classificação e de percepção, que produzem figuras a partir das quais o presente pode adquirir sentido inteligível e um espaço a ser decifrado, pois as representações não são neutras, elas apresentam estratégias e práticas (sociais, escolares, políticas) de coerção e convencimento que impõem uma autoridade à custa dos outros ${ }^{14}$.

As quatro edições da obra Parto Natural (1955, 1957, 1960 e 1964), publicadas pela Livraria Atheneu, são o corpus documental principal deste estudo. O livro original é oriundo dos Estados Unidos e sua primeira edição foi publicada em 1950. Diante da necessidade de constar o processo de ampliação e aprofundamento da temática, mediante a visão atual da história, especialmente da história cultural da parturição, para auxiliar a análise da pesquisa, outros suportes escritos relacionados a este assunto foram utilizados.

\section{As práticas destinadas ao corpo grávido vistas como forma de representar um modelo industrializado de parir}

O corpo é falado, invadido, investigado e (re) significado por diversas áreas do conhecimento. Ele se coloca como epicentro de muitos processos que, por decomposição, ingerência e recomposição, buscam formatar sua aparência, reconstruir 
suas falhas, redefinir ou potencializar suas funções e prolongar sua existência ${ }^{21}$. Ele é percebido, significado e vivido de maneira conflituosa, distinta e ambígua, de modo que as formas de vivê-lo abrangem os verbos "ser", "ter", "fazer", "controlar" e "cuidar". Dito de outra maneira, ele envolve o disciplinamento, a coerção, a subordinação, a saúde, a libertação, o gozo e o prazer $^{21}$.

Compreende-se que a representação do corpo foi histórica, social e culturalmente construída. O corpo grávido não está distante desse processo de construção, e isso pode ser certificado na obra Parto Natural. Nela foram ordenados muitos cuidados prescritivos, descritos no corpus do texto desde o seu começo, para obter a atenção, a perfeição e a saúde do corpo feminino, a fim de promover partos e nascimentos seguros, hospitalizados e recém-nascidos saudáveis - livres dos riscos.

Em seu decorrer foram pormenorizadas técnicas disciplinares investidas de saber médico com vista a promover no imaginário das futuras mães um modelo de parto "ideal", "imaginário" ou "sonhado". Para isso, é determinada uma intensa vigilância, gerada pela realização de exames, prescrição de vitaminas, alimentação, exercício físico, preparo dos mamilos e períneo, respiração, relaxamento, entre outros cuidados prescritivos. Todos visam prever ou prevenir completamente a maioria das complicações gestacionais e do parto e remediá-las antes do nascimento ${ }^{6}$. Em outras palavras, essas intervenções podem ser vistas como um trabalho de manutenção e identificação de imperfeições ou falhas de funcionamento ${ }^{22}$.

A representação da figura médica equivale à daquele profissional que é capaz de monitorar e corrigir qualquer defeito. A mulher grávida deve seguir todos esses cuidados, e qualquer conduta diferente da prescrita deverá ter, incialmente, o consentimento do médico ${ }^{6}$. Diferentemente do que é pregado na obra, uma representação otimista da gestação, assimila-se esse processo como cansativo, contínuo e estratégico, exige da mulher muitos sacrifícios.

A atenção e o controle médico também podem ser notados durante o processo do parto, por exemplo na história ficcional de "Vera", que seguiu todos os preceitos do livro Parto Natural. Ela foi contada no começo da obra e nos transmite a imagem de uma mulher preparada para uma das experiências mais profundas da vida, o nascimento, o que justificou o seu esforço ao realizar todas as condutas prescritas pelo médico, atreladas ao curso preparatório e à leitura de livros durante a gestação ${ }^{6}$. Trata-se de um relato narrativo, com uma linguagem simples e acessí- vel, que explica a importância de receber informações corretas durante a gestação e institui uma determinada forma de parir.

Ao analisar a história de "Vera" constata-se que ela objetiva representar a teoria "Parto Natural", que foi promovida pelos médicos Frederick Goodrich, Herbert Thoms e Robert Wyatt, e teve início nos anos de 1947, na Universidade Yale $^{23}$. Um relato sobre a experimentação dessa teoria foi registrado em 1948, e os médicos concluíram que o "Parto Natural" era um método que poderia ser transmitido em um serviço de ensino e que oferecia vantagens para a mãe e a criança. No livro era defendida a ideia de que o parto é um processo natural do corpo da mulher e é fundamental que ela reconheça o seu potencial de trazer o bebê ao mundo. Assume-se que a parturiente representa o papel principal e que é importante que ela esteja preparada física e emocionalmente ${ }^{24}$.

O idealizador Frederick Goodrich preconiza que a teoria não pode ser comprovada em laboratório, mas o número de serviços que estavam realizando era frequente. Naquela época, na cidade de Nova York, o Ministério da Saúde recomendou a inclusão desse Programa nos hospitais e clínicas de pré-natal ${ }^{23}$. No entanto, de acordo com o obstetra Fernand Lamaze et al. ${ }^{25}$, "O parto natural, longe de ser uma generalização nos Estados Unidos, limita-se a alguns centros de experiência". Para a médica Heynemann ${ }^{26}$, "parece haver nos Estados Unidos uma superestimação pela técnica e certo desprezo pelos processos naturais e fisiológicos, o que se traduz pelos $50 \%$ de fórceps e $6 \%$ de cesarianas nos partos". As principais ferramentas utilizadas pelos obstetras americanos na década de 1950 foram o fórceps, para extrair o bebê, e a tesoura, para cortar o períneo, devendo ser ressaltado que naquela época a cesárea estava em ascensão ${ }^{27}$. O aumento significativo dos partos por via alta se deu, principalmente, a partir dos anos de 1960. Porém, durante esse período de transição, os partos se concentraram nos hospitais e era fácil convencer as mulheres que a melhor forma de parir era nesses locais e próximos ao centro cirúrgico ${ }^{27}$.

Acredita-se que com o intuito de institucionalizar a teoria "Parto Natural" e apresentar os benefícios de um parto hospitalar assegurado pelas mãos de um médico, Frederick Goodrich utilizou estrategicamente uma obra destinada principalmente para as gestantes, para garantir, por meio do seu corpo, a realização desses objetivos. Ao ler a história de "Vera", entende-se que ela estava preparada para o parto normal e hospita- 
lar. No entanto, questiona-se o modelo de preparação para o parto proposto pelo livro.

Os anos de 1950 foram marcados pela disseminação de métodos de preparação para o parto. Os médicos Dick Read e Fernand Lamaze também instituíram teorias, o "Parto Sem Temor" e o "Parto Sem Dor", respectivamente1. Apesar de possuírem distinções, visavam reduzir o medo e aliviar o sofrimento do parto por meio da preparação da mulher. Inclusive, constata-se que "Vera" não teve medo do parto e nem das dores das contrações uterinas em virtude do conhecimento adquirido ${ }^{6}$. O livro Parto Natural possui uma parte sobre a fisiologia e a psicologia do trabalho de parto direcionada à ciência médica ${ }^{6}$.

A teoria "Parto Natural", entre outras mencionadas, defende o preparo mental da mulher e destaca as questões emocionais distintamente dos tratados de obstetrícia. O livro relaciona o medo e o trabalho de parto:

Supõe-se que as contrações se iniciem no próprio útero, mas estejam sob a influência das duas subdivisões do sistema nervoso involuntário, isto é, o parassimpático e o simpático; isto significa que impulsos nervosos involuntários do cérebro afetam o trabalho de parto e que estes impulsos nervosos podem ser influenciados por estados emocionais ${ }^{6}$.

E ainda explica:

A bôlsa muscular que forma o útero é constituída por um complexo intrincamento de fibras musculares involuntárias. Se estas fibras fôssem voluntárias, as mulheres poderiam dar início ao trabalho de parto quando assim desejassem $e$, à primeira vista, isto poderia parecer um atributo bastante desejável ${ }^{6}$.

Nota-se como o corpo da mulher e o útero são citados: passa-se a ideia de que o trabalho de parto iniciará independentemente da vontade da mulher. A própria palavra trabalho remete ao serviço a desempenhar por algo ou por alguém em uma fábrica. Para entender esse processo, é necessário reconhecer que no desenvolvimento da medicina ocidental revela-se a metáfora do corpo como uma máquina e do médico como mecânico: se o médico for o supervisor, a mulher será a trabalhadora, cuja máquina, o útero, produz o produto, o recém-nascido (um bem social) ${ }^{22}$. Apesar de abordar os aspectos emocionais, nota-se a relação clara de poder entre a mulher e o médico em um trabalho fabril.

A obra esmiúça cada fase de trabalho de parto: o início, a primeira, a segunda, a terceira e a quarta fase ${ }^{6}$, com tempos bem determinados, mensurados e precisos. Essa subdivisão é comparada com um trabalho fabril, e em cada estágio é necessária uma vigilância constante por parte do médico. Esse gerenciamento científico determina que a parturiente seja realmente um sujeito a ser controlado $^{22}$. Todavia, apesar de visar monitorar o corpo da mulher, o livro destaca que o conhecimento detalhado desse processo proporciona um resultado positivo para ela ${ }^{6}$ : o autocontrole que por meio do conhecimento pode ser conseguido mesmo sem a presença de qualquer figura de autoridade (médica) ${ }^{28}$.

A noção de representação demonstra um duplo sentido e uma dupla função: de tornar presente uma ausência, mas também de exibir sua própria presença como imagem e, assim, constituir aquele que a olha como sujeito que olha e é capaz de ver, pensar e crer ${ }^{15}$. Desse modo, pelos gestos e comportamentos das mulheres durante o parto seria possível reconhecer a teoria "Parto Natural" e todos os ensinamentos prescritos pela autoridade médica. Portanto, o autodomínio também seria atingido, o que, de certo modo, contribuiria para o trabalho do médico e de outros profissionais de saúde.

$\mathrm{Na}$ obra acrescenta-se que o conhecimento adquirido pela mulher poderia ser colocado em prática: "Vera já sabia o que teria que se submeter e com isso, ela já começou a relaxar e, à medida que o médico empregasse os termos médicos, ela o compreendia e se sentia feliz por estar sendo tratada como participante ativa no trabalho de parto"'. Na seção de Psicologia, ressalta-se:

A esta altura é que você deve começar a por em prática as técnicas de relaxamento que aprendeu. A primeira fase de trabalho de parto é de todo involuntária [...] Se você contrair seus músculos voluntários quando o útero estiver se contraindo, verá que será extremamente incômoda a sensação provocada pela contração [...] O incômodo que resulta disto aumentará a tendência a repetir estas ações durante a próxima contração e logo você estará dominada por êste círculo vicioso. Se você assumir a posição lateral e, conscientemente, relaxar os músculos voluntários, estará pronta para iniciar a respiração diafragmática, quando começarem as contrações [...] Se a cabeça da criança já estiver baixa na pelve, você sentirá, subitamente, vontade de empurrar ou fazer fôrça para baixo. Se você reagir a essa vontade tomando uma respiração profunda, prendendo-a e fazendo fôrça para baixo por meio de contração dos músculos abdominais, verá que a contração do útero não causa dor ${ }^{6}$.

Deve-se ressaltar como a autonomia da mulher é retirada diante do parto: cabe somente ao útero o trabalho, pois se trata de uma ação muscular involuntária. Se a mulher não realizar efe- 
tivamente as instruções apreendidas, provavelmente haverá o aparecimento da dor, substituída pela palavra incômodo. A mulher não podia ir ao encontro do seu corpo ou de suas vontades, ela precisava seguir todos os cuidados prescritos a fim de garantir o sucesso de um "parto natural" e sem dor, caso contrário, a culpa seria dela.

A realização da respiração deve estar atrelada a uma determinada posição específica e aos métodos de preparação para o parto: "treina as mulheres para controlar as suas respirações, seus pensamentos e a expressão de suas emoções"27,28. Esses métodos possuem comandos precisos como: inspire, expire, controle sua respiração e/ ou força, isto é, demonstram um parto mecânico e técnico ${ }^{27}$. Eles são disciplinares, visam ao autocontrole e impedem as mulheres de se movimentarem e vivenciarem um parto, de acordo com suas aspirações e vontades.

Ressalta-se que o cenário do parto exposto na obra possibilita a supervisão dos modos de parir, ao fazer uso de técnicas ou procedimentos postulados pela ciência, portanto ele se torna hipermedicalizado. Esse saber médico funciona como o porta-voz das mulheres, o que a conduzirá a uma forma de parir e sob um determinado poder. Postula-se uma configuração de um modelo de coerção no qual o corpo grávido se submete e se ajusta conforme a peça de uma máquina. Ocorre uma manipulação calculada, governada, de cada elemento, de cada gesto e do comportamento da parturiente.

A título de ilustração, "Vera" começou a sentir contrações uterinas com intervalos menores, e com isso imaginou que estivesse no final da primeira fase de trabalho de parto. O médico confirmou sua suspeita, e ela foi levada para a sala de parto e colocada em uma posição supina ${ }^{6}$. Esta posição adotada pelas parturientes não oferece à mulher muitas escolhas de atitude e impede o seu movimento ${ }^{27}$. A única atitude que lhe é garantida é fazer força para baixo, a fim de facilitar a expulsão do feto. Sabe-se que essa posição passou a ser utilizada no período expulsivo, quando Luiz XIV queria assistir ao parto de sua amante atrás da cortina ${ }^{29}$. E com a entrada do homem no cenário do parto, pela primeira vez foi exigido que mulher desse à luz deitada, visando facilitar o emprego do fórceps pelos médicos. Eles, com suas ferramentas (pinça, tesoura e fórceps) em mãos, posicionam-se na frente da mulher passiva ${ }^{27}$.

Na obra é frequentemente mencionada a prática de empurrar para baixo, o preparo físico do períneo e o uso da episiotomia, de acordo com os excertos:
A ação do músculo uterino pode ser auxiliada, durante a segunda fase, pelas contrações dos músculos voluntários da parede abdominal. Esta é a ação de empurrar ou fazer fôrça para baixo, que se assemelha à executada quando se trata da exoneração dos intestinos ${ }^{6}$;

Quando os tecidos que envolvem o canal de nascimento são rígidos e inelásticos, sua distensibilidade se torna menor e a segunda fase pode ser mais dificil e durar muito mais tempo. Torna-se, assim, óbvia a necessidade de preparo físico ${ }^{6}$;

Os exercícios que foram descritos visam corrigir a inelasticidade dos músculos e desenvolvê-los a ponto que possam oferecer um apoio adequado. Se porém, você não conseguir aumentar a eficiência dêstes músculos a êsse ponto, sempre se poderá fazer uma episiotomia ${ }^{6}$;

Não há razão para acreditar que a episiotomia seja antinatural ou devida a um fracasso de sua parte. Se você fêz tudo que pôde para desenvolver a eficiência dos músculos do períneo, talvez que a episiotomia não se torne necessária mas, de qualquer modo, você sempre terá a satisfação de haver se esforçado, tanto quanto possivel, na preparação para o seu parto

Esses fragmentos refletem a situação submissa que a parturiente vivencia, que vê sua autonomia e sua espontaneidade do parto sendo retiradas. Entretanto, o profissional médico que assiste a parturiente tem uma situação de total controle sobre o corpo da mulher e sobre o parto, e, acima de tudo, o poder de crer, ver e fazer, pois "Vera" pode fazer todos os exercícios ensinados durante a gestação, mas durante o período expulsivo solicitou a máscara de gás, e em seguida houve a necessidade de fazer a episiotomia: "O médico disse a Vera que era necessário fazer uma incisão para que a criança saísse mais ràpidamente. Injetou algum anestésico local antes de incisar, de modo que Vera nada sentiu. Aliás, ficou surprêsa quando êle disse que estava tudo terminado"6.

Algumas questões importantes e dicotômicas são reveladas. No segundo estágio de trabalho de parto, a mulher é vista como participante e preponderante do processo, pois ela precisa fazer força durante o período expulsivo. Porém, "Vera" foi "incapaz" de expulsar o seu feto, pois conforme a lógica da produção de uma fábrica é preciso parir rapidamente. Daí a necessidade da assistência de um profissional médico e a realização da episiotomia.

Compreende-se, por um lado, que o livro é um impresso cultural que enfatizava a competência da mulher em participar ativamente do seu ato de parir por vias normais. Na segunda 
fase de trabalho de parto, ela pode fazer força, controlar e regular o seu próprio corpo. Mas, por outro, a obra "Parto Natural" delimita que o períneo pode ser inelástico ou não foi preparado adequadamente, que a mulher não está apta para parir, entre outras imperfeições do corpo e da mente. Com efeito, nas entrelinhas estão a invisibilidade e a tenacidade do processo de ordenamento por uma autoridade médica. Em relação ao uso das palavras, deve-se ter consciência dos efeitos subliminares que elas apresentam no evento do parto e nascimento. Sugere-se evitar o uso de expressões como tutorar, guiar e apoiar, pois possuem efeito condicionador ${ }^{27}$. Esses elementos presentes contribuem para a representação de que as mulheres não estão aptas para parir e que elas necessitam de outros para realizá-lo.

Contudo, ressalta-se que a didática da gestação é uma socialização consciente e necessária para recuperar a autonomia abortada ${ }^{30}$. Objetiva-se aprender e treinar técnicas corporais que foram desaprendidas à medida que o parto deixou de ser assunto de mulheres e passou para o campo médico, tornando-se um saber muitas vezes inacessível à maioria das mulheres. A pedagogia do parto se coloca como uma tarefa da mulher moderna que escolhe dar à luz, que é dona de seu corpo e de sua sexualidade ${ }^{31}$.

Corrobora-se aqui com essas ideias, porém constata-se que a circulação do livro Parto Natural tem duas faces opostas. A primeira é sobre a pedagogia do parto, que visa resgatar o protagonismo da mulher no ato de parir. A preparação da mulher durante a gestação estava baseada na educação, e esse cuidado parte do pressuposto que o parto é muito mais que um processo biológico, ele é também cultural. A segunda face contrária é revelada após uma leitura intensiva desse livro. Evidencia-se que apesar de acreditar e proclamar uma assistência centrada na parturiente, visando ao seu ativismo no momento do parto por meio da educação, cabia ao médico, por meio de sua presença ou de sua presentificação de uma ausência (através do livro), o papel de preparar a gestante. Ele conseguia consolidar em sua figura a função de mãe, de pai, de amigo e de companheiro. Através dos corpos das mulheres, ele conseguia legitimar e institucionalizar sua forma de pensar, agir e parir. De fato, é um processo normatizador; de se fazer reconhecer, de se autoafirmar e de estar no campo obstétrico. Acredita-se que a pedagogia do parto gera uma consequência: a escravização da mulher aos diversos modelos de partos que as deixam prisioneiras, em vez de atentarem às vontades e aos de- sejos do próprio corpo. Dependendo do ângulo de análise, uma face pode ser mais acentuada que a outra, contudo a segunda é mais fácil de ocultar do que a primeira.

A obra convoca a mulher a passar por um processo de reeducação, no sentido de incutir nela a representação de um parto industrializado por meio da representação de um parto natural. Legitima, a cada momento, o papel do médico no processo parir e a incapacidade da mulher de fazê-lo. O livro defende, além das imperfeições supracitadas, que as contrações uterinas podem não ser suficientes ou não estar em um ritmo considerado correto pela especialidade médica. É notório o controle dos tempos do parto e os procedimentos de acelerações: "Seu médico empregará êstes meios de induzir ou reforçar a eficiência do trabalho de parto se forem necessários e indicados. Seria tolice sua pretender que êle os empregasse sòmente para satisfazer algum capricho seu o porque você está muito ansiosa para que o bebê nasça"6.

Evidencia-se que apenas a vontade médica é ponderada e que a escolha não é da mulher. Cabe ainda considerar que muitas condutas prescritas são inibidoras do trabalho de parto, por exemplo, as rotinas hospitalares. Foi possível perceber algumas padronizações dos procedimentos no livro: toque vaginal, tricotomia (raspagem dos pelos pubianos), lavagem intestinal, ruptura das membranas ovulares, episiotomia, fórceps e posição supina. Porém, não basta observar a rotina como mera curiosidade ou como um cuidado qualquer, no qual o leitor se surpreende apenas com algo que lhe é estranho. Trata-se de trazer o passo a passo, de modo que a mulher ou nós leitores possamos tornar compreensível cada momento, sua constituição e sua funcionalidade na configuração do cenário do parto, cujo ordenamento é nítido. A obra põe em evidência a importância de cada ato; em um sentido mais restrito, quanto ao seu tipo de dominação; e em um sentido mais amplo, uma verdadeira linha de produção ou montagem em uma fábrica, a saber, o processo do parto. Essa rotina segue uma hierarquia muito precisa, em que cada atitude revela um sinal de prestígio, de divisão, de poder, enfim, um meio de subsistência médica.

Com o propósito de demonstrar essa subsistência, no ápice do período expulsivo foi ofertada à "Vera" uma máscara de gás para cheirar", o que provavelmente não lhe permitiu participar ativamente do seu trabalho de parto. Porém, conforme a história de "Vera", ela procurou obedecer às ordens, e após o alívio da pressão ela conseguiu 
ver a criança nas mãos dele ${ }^{6}$. A partir de então: "Vera se sentiu emocionada e quis levantar-se para segurar a criança, mas a enfermeira que estava à cabeceira da mesa já lhe avisara para não fazer, pois os panos que a cobriam estavam esterilizados" ": "O médico colocou a criança sôbre o abdome de Vera e, enquanto o fazia, o bebê dava início a um valente choro"6.

Diante disso, no decorrer dessa história é possível perceber a clareza que "Vera" tinha dos acontecimentos ao seu redor e dos cuidados que eram realizados com o seu bebê. Esse fato levou a crer que ela participou ativamente do parto. Essa percepção também pode ser notada pelo leitor, apesar de se tratar de uma situação hipotética. Explicitamente, "Vera" declarou sua emoção diante do seu parto e acreditou que havia ajudado seu filho nascer ${ }^{6}$. Mas, implicitamente, ocorre uma afirmação ativa ao lado de uma aceitação passiva. As representações são detentoras de uma energia própria que convence seus leitores e espectadores que o real corresponde efetivamente ao que elas afirmam e demonstram ${ }^{32}$. Elas estabelecem uma imposição com vista a produzir a interiorização e se põem como uma máquina de fabricar respeito e submissão, onde falta, quando necessário, o recurso à força bruta ${ }^{15}$.

\section{Considerações finais}

Diante dessa dinâmica complexa e dicotômica apresentada por intermédio da história de "Vera" e ao longo do livro Parto Natural, destaca-se que ela tem como premissa principal e básica institucionalizar a representação do parto industrializado. Ao traçar uma teia de propostas de intervenção dirigidas às mulheres em meados do século XX, apresenta como finalidade nítida o ordenamento das parturientes para a promoção da teoria Parto Natural.

Por fim, indaga-se: qual é a representação atribuída ao médico? E do livro Parto Natural? Acredita-se que elas, em conjunto, são vistas predominantemente como fundamentais para o estabelecimento de uma forma de parir. Por meio delas, reforça-se aquela antiga expressão: “o médico é que fez o meu parto!” Cabe ao médico, por meio da obra, passar todas as informações necessárias para a mulher. Cabe a ele intervir, quando necessário, por meio da aplicação de medicamentos indutores ou aceleradores em caso de um trabalho de parto insuficiente. Cabe a ele prescrever analgésicos ou anestésicos, a fim de aliviar a dor. Cabe a ele realizar a ruptura das membranas amnióticas ou executar a episiotomia, entre outros procedimentos rotineiros. Cabe a ele proporcionar à mulher um "parto natural", excluindo ela de qualquer tipo de decisão. A partir da crença desse livro, transforma-se a forma de ser, ver, saber e viver o parto.

Diante essas suposições, ingerências e reações, questiona-se como as mulheres perceberam esse controle de seus corpos. Será que aceitaram naturalmente tantas imposições? Ou será que reagiram ao projeto pedagógico do parto? Acredita-se que, diante do atual modelo obstétrico brasileiro, sobretudo com a epidemia de cesariana, a maioria das mulheres não parece estar ciente dessa passividade implícita no livro. Porém, mesmo com as fronteiras bem limitadas e aparentemente inflexíveis e rígidas, existem aquelas cujos comportamentos são rebeldes e vadios.

Embora o livro nos convide a olhar para a possibilidade de um parto natural, praticamente sem dor, centrado na mulher, fica claro que o autor pensa constantemente em termos de modernidade, ciência, progresso e industrialização do parto. $\mathrm{O}$ assunto é ampliado com um pequeno número de alusões preponderantes e bem colocadas, com vista a proteger a mulher, e com diversos dispositivos que facilitam o ocultamento de um ordenamento que se mantém até os dias atuais. O modelo de parto pregado não é de um parto natural à luz da vontade das mulheres; ele é medicalizado e institucionalizado. Essa configuração leva a ver e a crer que a figura do médico é percebida como aquele que previne as sequelas do parto e do nascimento. Essa concepção foi sustentada ao longo do século XX e permanece no cotidiano das maternidades brasileiras, pois o parto normal ainda é visto como patológico por parte da sociedade e pelos profissionais de saúde.

Ademais, o termo parto natural é polissêmico, uma vez que, conforme a concepção adotada, determina a prática a ser desenvolvida pelo profissional de saúde ou pela mulher. É preciso admitir que se deve ofertar às mulheres um cuidado respeitoso, mútuo, qualificado, sem a onipotência e autoridade do profissional de saúde, considerando as especificidades de cada mulher, suas escolhas e seu projeto de vida. Nesse universo do parto existe um lugar para cada tipo: no domicílio, no hospital, na maternidade, casa de parto, centro de parto normal, de cócoras, de quatro apoios, deitado, semi-sentado, com companheiro, sem companheiro, com analgesia, sem analgesia, normal ou cesáreo. De certo, cada um tem suas vantagens e desvantagens e cada mulher é diferente, portanto cada parto também é diferente. 


\section{Colaborações}

LFA Ayres participou suficientemente da autoria do manuscrito na introdução, método, resultados/discussão e considerações finais e na redação final. BD Henriques participou suficientemente da autoria do manuscrito na redação final. WM Amorim participou suficientemente da autoria do manuscrito na metodologia e na redação final.

\section{Referências}

1. Diniz CSG. Humanização da assistência ao parto no Brasil: os muitos sentidos de um movimento. Cien Saude Colet 2005; 10(3):627-637.

2. Leal MC, Pereira, APE, Domingues, RMSM, Filha, MMT, Dias, MAB, Pereira-Nakamura M, Bastos, MH, Gama SGN. Intervenções obstétricas durante o trabalho de parto e parto em mulheres brasileiras de risco habitual. Cad Saude Publica 2014; 30(Supl.): S17-S47.

3. Souza JP, Pileggi-Castro C. Sobre o parto e o nascer: a importância da prevenção quaternária. Cad Saude Publica 2014; 30(Supl.):S11-S13.

4. World Health Organization (WHO). Maternal and Newborn Health/Safe Motherhood Unit. Care in normal birth: a practical guide. Geneva: WHO; 1996.

5. Nagahama EEI, Santiago SM. A institucionalização médica do parto no Brasil. Cien Saude Colet 2005; 10(3):651-657.

6. Goodrich FWJ. Parto Natural: Guia para os futuros pais. Rio de Janeiro: Livraria Atheneu LA; 1955.

7. Lima ALG. Recomendações médicas para a educação da criança-problema: um estudo de manuais de higiene mental, 1939-1947. História, Ciências, Saúde 2013; 20(1):317-325.

8. Lima ALG. Maternidade higiênica: natureza e ciência nos manuais de puericultura publicados no Brasil. História: Questões \& Debates 2007; 47:95-122.

9. Santos CA. A vida do bebê: a constituição de infâncias saudáveis e normais nos manuais de puericultura brasileiros. Revista Brasileira de Educação 2011; 16(4):427518.

10. Freire MML. Mulheres, mães e médicos: discurso maternalista em revistas femininas. (Rio de Janeiro e São Paulo, década de 1920) [tese]. Rio de Janeiro: Casa de Oswaldo Cruz; 2006.

11. Freitas P. Corpos de Mulheres em (re)vista. A representação da menopausa na Revista de Ginecologia e d' Obstetrícia 1907-1978 [tese]. Santa Catarina: Universidade Federal de Santa Catarina; 2005.

12. Foucault M. A arqueologia do saber. $4^{\mathrm{a}}$ ed. Rio de Janeiro: Forense Universitária; 1995.

13. Bourdieu P, Chartier R. A leitura: uma prática cultural. In: Chartier R, organizador. Práticas da leitura. São Paulo: Estação da Liberdade; 2009. p. 229-254.

14. Chartier R. A História Cultural: entre práticas e representações. Lisboa: Difel; 1988.

15. Chartier R. À BEIRA da falésia: a história entre incertezas e inquietude. Porto Alegre: Editora Universidade/ UFGRGS; 2002.

16. Lasch C. Refúgio num mundo sem coração. A família: santuário ou instituição sitiada? Rio de Janeiro: Paz e Terra; 1991.

17. Elias N. O processo civilizador: uma história dos costumes. $2^{\text {a }}$ ed. Rio de Janeiro: Zahar; 2011.

18. Brenes AC. História da parturição no Brasil, século XIX. Cad Saude Publica 1991; 7(2):135-149.

19. Mott ML. Assistência ao parto: do domicilio ao hospital (1830-1960). Proj. Historia 2002; 25:197-219.

20. Leister N, Riesco MLG. Assistência ao parto: história oral de mulheres que deram à luz nas décadas de $1940 \mathrm{a}$ 1980. Texto Contexto Enferm 2013; 22(1):166-174.

21. Meyer DE. Corpo, gênero e maternidade: algumas relações e implicações com o cuidado em saúde. Enfermagem em Foco 2011; 2(1):18-22. 
22. Martin E. A mulher no corpo: uma análise cultural da reprodução. Rio de Janeiro: Garamond; 2006.

23. Goodrich FWJ. The Theory and practice of natural childbirth. Yale Journal of Biology and Medicine 1953; 25(6):529-534.

24. Thoms H, Wyatt RH. A Natural Childbirth Program. Am J Public Health Nations Health 1950; 40(7):787-791.

25. Lamaze F, Anguelergues R, Bourrel A, Vellay P, Hersillie H, Guay FL, Pavlov IP. Parto Sem Dor. Revista Atualidade Médica e Biológicas, Editora Vitória Ltda.; 1956.

26. Heynemann TH. Modificações e progressos na obstetrícia e ginecologia do estrangeiro e sua significação para a nossa especialidade. Anais Brasileiros de Ginecologia 1950; 29(XV).

27. Odent M. O Renascimento do parto. Florianópolis: Saint Germain; 2002.

28. Foucault M. Microfísica do poder. $11^{\mathrm{a}}$ edição. Rio de Janeiro: Graal; 1989.

29. Balaskas J. Parto ativo: guia prático para o parto natural. São Paulo: Ground; 1993.

30. Salem T. O ideário do parto sem dor: uma leitura antropológica. Boletim do Museu Nacional 1983; 40:1- 27.

31. Tornquist CS, Spinelli CS. Um jeito soviético de dar à luz: o parto sem dor no sul da América do Sul. Historia Oral 2009; 12(1-2):129-156.

32. Chartier R. Defesa e ilustração da noção de representação. Fronteiras 2011; 13(23):15-29.

Artigo apresentado em 27/04/2016

Aprovado em 29/11/2016

Versão final apresentada em 01/12/2016 